\title{
Influence of lubrication, tool steel composition, and topography on the high temperature tribological behaviour of aluminium
}

\author{
Justine DECROZANT-TRIQUENAUX ${ }^{1,{ }^{*}}$, Leonardo PELCASTRE ${ }^{1}$, Braham PRAKASH $^{1,2}$, Jens HARDELL ${ }^{1}$ \\ ${ }^{1}$ Machine Elements, Luleå University of Technology, Luleå SE-97187, Sweden \\ ${ }^{2}$ Department of Mechanical Engineering, Tsinghua University, Beijing 100084, China \\ Received: 12 September 2019 / Revised: 11 December 2019 / Accepted: 12 February 2020 \\ (C) The author(s) 2020 .
}

\begin{abstract}
The use of high strength aluminium alloys, such as 6XXX and 7XXX series, is continuously increasing for automotive applications in view of their good strength-to-weight ratio. Their formability at room temperature is limited and they are thus often formed at high temperatures to enable production of complex geometries. Critical challenges during hot forming of aluminium are the occurrence of severe adhesion and material transfer onto the forming tools. This negatively affects the tool life and the quality of the produced parts. In general, the main mechanisms involved in the occurrence of material transfer of aluminium alloys at high temperature are still not clearly understood. Therefore, this study is focussed on understanding of the friction and wear behaviour during interaction of Al6016 alloy and three different tool steels in as-received and polished state. The tribotests were carried out under dry and lubricated conditions, with two distinct lubricants, using a reciprocating friction and wear tester. The worn surfaces were analysed using scanning electron microscopy (SEM) and energy dispersive X-ray spectroscopy (EDS). The results showed a high dependence of friction and wear behaviour on the tool steel roughness as well as on the stability of the lubricant films. Tribolayers were found to develop in the contact zone and their capacity to improve the tribological behaviour is seen to be drastically impacted by the surface roughness of the tool steel. When the tribolayers failed, severe adhesion took place and led to high and unstable friction as well as material transfer to the tool steel.
\end{abstract}

Keywords: friction; wear; high temperature tribology; aluminium; lubrication; tribolayer

\section{Introduction}

In order to comply with the increasingly stringent emission regulations, passenger safety, as well as the considerations of added weight of e.g. batteries for electric vehicles, the automotive industry is turning towards the use of materials with high strength-to-weight ratio. High strength aluminium alloys, such as the 6XXX and 7XXX series, are examples of materials that can meet these demands. Novel lightweight design solutions can be realised by combining high-strength steel and aluminium into the body-in-white structure of passenger cars.

In order to manufacture complex shaped components, hot forming of aluminium is usually the preferred production method [1]. Forming at high temperature minimises spring-back [2] and improves formability compared to cold forming [3, 4]. High temperature forming of aluminium, as for example the "hot forming and quenching" (HFQ $\left.{ }^{\circledR}\right)$ process, involves various heat treatments [4,5]. This process involves pre-forming solubilisation, quenching as well as ageing, in order to get sufficient mechanical properties and surface quality of the formed components

* Corresponding author: Justine DECROZANT-TRIQUENAUX, E-mail: justine.decrozant-triquenaux@1tu.se 
[1-5]. The contact between the dies and the aluminium alloy sheets is a complex tribological interface that, when not properly optimised, can adversely affect the entire process efficiency and quality of the produced parts. Aluminium alloys are known to result in severe adhesion (also termed as seizure and galling) when sliding against steels and other harder metals both at low and elevated temperatures $[1,6,7]$. Severe adhesive material transfer increases the need for frequent maintenance of the tools and adversely affects the economy of the process [4]. Furthermore, the hard aluminium oxide on the soft aluminium can fracture during deformation thus contributing to abrasive wear damage of the tool surface as well as occurrence of galling $[1,8$, 9]. The adhesive and abrasive wear of the tools also have a detrimental impact on the surface quality and the dimensions of the formed components [6, $10,11]$.

Sliding contacts involving aluminium alloys at high temperature are generally associated with high friction levels, due to their chemical reactivity and softening at elevated temperatures $[6,12]$. The sliding wear response of aluminium alloys has been divided into two regimes in the literature [12-14]: the mild wear regime, with low wear rates and oxidised tribolayers; and the severe wear regime, with significant plastic deformation, high adhesion, and transfer of aluminium to the counter surface [14, 15]. The transition between these regimes is governed by operating parameters such as load, temperature, and microstructural changes $[14,16]$.

Typical solutions to alleviate issues associated with wear and high friction are the use of lubricants as well as surface engineering strategies, as reported by Krajewski et al. [17] and Pelcastre et al. [18].

Common metal forming lubricants include oilbased lubricants, emulsions, and greases, and all these make use of specific additives (graphite, $\mathrm{MoS}_{2}$, and boron compounds among others) [19, 20]. Lubrication at high temperatures is however limited by the physical and chemical changes occurring at elevated temperatures, resulting in rapid degradation of the lubricant [17]. Special lubricant formulations for high temperatures are thus required.

Hexagonal boron-nitride is commonly used as a high temperature additive in greases and oils [21] and its use as a solid lubricant for aluminium forming is increasing [22]. Its lamellar structure exhibits friction and wear reducing properties as well as chemical stability at high temperatures, making it a potential candidate for these applications [22]. On the other hand, polymeric lubricants [20, 23] and ionic liquids [24] have also been investigated as suitable high temperature lubricants for metal processing. Wan et al. [20] reviewed potential polymeric lubricants and concluded that specific polyphosphates are promising anti-wear additives for hot metal working applications. Their study focussed mainly on lubrication of a steel-steel contact. Jiménez et al. [24] tested ionic liquids as potential lubricants since ionic liquids exhibit good thermal stability at elevated temperatures. They found that protective layers could form at the steel-aluminium interface as a result of tribochemical reactions with the ionic liquids. Friction as well as wear were found to be directly linked to the properties of those layers during the tribotests. They limited their study to testing temperatures up to $200{ }^{\circ} \mathrm{C}$. To date however, only a few commercial lubrication strategies for hot forming application have been reported and there is still inadequate knowledge in this field [17, 20, 24].

The importance of surface topography of contacting solids has been discussed in the open literature. Different researchers have highlighted the influence of the surface finish of the dies on the initiation and development of aluminium transfer, at both low and high temperatures $[1,9,25,26]$.

Heinrichs [25] evaluated the impact of surface topography parameters of tool steels on galling during cold forming. The results showed that on rough tool steel samples, the transfer of aluminium initiated and developed from grinding scratches and local surface defects. In dry conditions, even mirror-polishing the tool steel samples could not prevent aluminium transfer. One of the main conclusions was that, despite optimised tool steel surface finish and composition, the only effective way to prevent the initiation of aluminium transfer 
is the use of lubricants. For high temperature processes, the information available in the open literature concerning the effect of the tool steel surface topography on aluminium transfer is limited. When considering lubricated conditions and elevated temperatures, the information available in the open literature is even more scarce.

Pujante et al. [9] reported, for dry and high temperature condition, that even mirror-polished surface finish cannot prevent the initiation of aluminium transfer. They identified that surface irregularities, such as grinding groove edges and polishing scratches, are nucleation sites for the aluminium transfer also at high temperatures.

Similarly, Gali [1] stated that the higher the tool steel surface roughness, the higher is the susceptibility of aluminium transfer to the mating surface. They concluded that, as transfer occurs, the roughness of the tool steel increases and leads to more unpredictable and severe tribological behaviour.

Even though the need for controlled topography of the dies and lubrication is acknowledged in hot processing of aluminium, their effect on friction and wear has not yet been investigated in sufficient depth. The recent developments of new lubricants and better understanding of the effects of specific formulations at room temperature [19] have resulted in a widened perspective for the tribological research field, yet to be translated to elevated temperatures [20]. The understanding of the mechanisms leading to galling during hot forming of aluminium alloys is also still limited.

The present study thus aims at bridging these knowledge gaps through characterization of the high temperature friction and wear response of tool steels sliding against aluminium. The effect of lubrication has been investigated by comparing two commercially available lubricants. The influence of tool steel composition as well as the effect of surface topography have also been studied.

\section{Experimental work}

\subsection{Materials}

The tribotests carried out in this study involved three commercially available tool steels, an aluminium alloy (AA6016) as the counter surface and two different commercially available lubricants.

In order to study the influence of tool steel composition, three tool steels were selected: Mo$\mathrm{Co}-\mathrm{Cr}-\mathrm{B}$ alloyed tool steel (further referred to as tool steel A), Cr-Mo-W-V-N-alloyed cold work tool steel (tool steel $\mathrm{V}$ ), and $\mathrm{Cr}-\mathrm{Mo}-\mathrm{V}$-alloyed hot work tool steel (tool steel $\mathrm{O}$ ). Their microstructures are shown in Fig. 1, showing the different carbide sizes and distribution in the steel matrix for each of the alloys. Their chemical composition (as provided by the supplier) as well as microhardness (measured in the laboratory) are given in Table 1. Tool steels A and $\mathrm{V}$ present similar hardness levels, whereas tool steel $\mathrm{O}$ exhibits a much lower hardness. All the tool steels nevertheless show significantly higher hardness levels than the aluminium counter-material.

The first lubricant considered for this study was a commercially available hexagonal boron-nitride based lubricant JK 41 from Zyp coatings Inc. This lubricant is formulated for superplastic forming processes and will be further referred to as hBN. The second lubricant was a commercially available white die lubricant Lubrodal F $25 \mathrm{Al}^{\circledR}$ from FuchsLubritech $\mathrm{GmbH}$. This lubricant is a siliconpolymer aqueous emulsion, formulated for warm forming of aluminium and especially forging, further
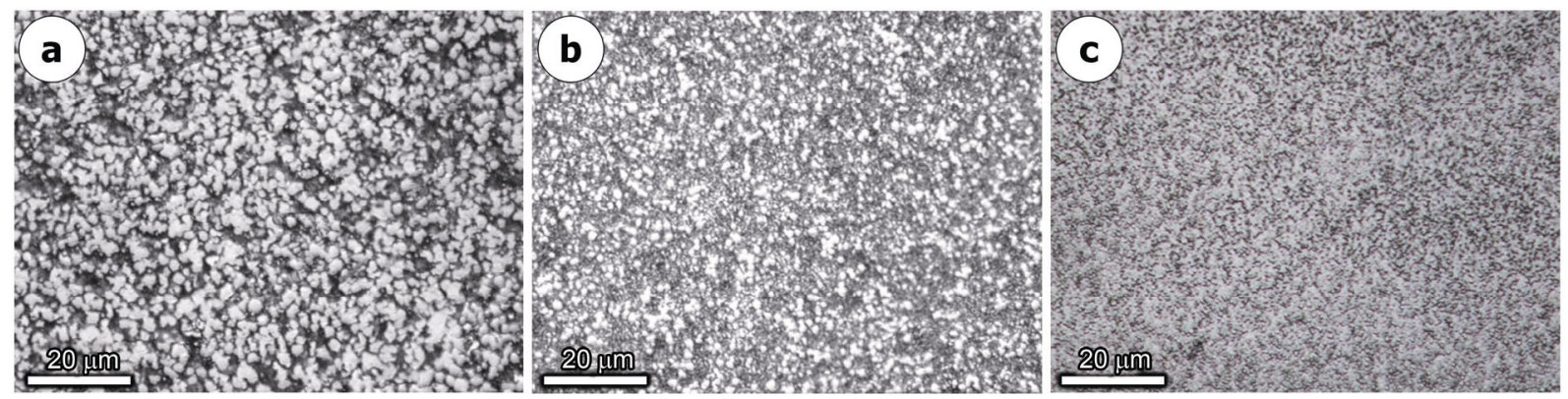

Fig. 1 Optical micrographs of (a) tool steel A, (b) tool steel V, and (c) tool steel O (magnification 1,000×). 
Table 1 Chemical composition (wt $\%$, as provided by the supplier) and measured microhardness of the investigated materials (Fe for the steels and $\mathrm{Al}$ for the aluminium make up the balance).

\begin{tabular}{ccccccccccccccc}
\hline Material & $\mathrm{C}$ & $\mathrm{Si}$ & $\mathrm{Mn}$ & $\mathrm{Cr}$ & $\mathrm{Mo}$ & $\mathrm{V}$ & $\mathrm{W}$ & $\mathrm{Co}$ & $\mathrm{B}$ & $\mathrm{N}$ & $\mathrm{Mg}$ & $\mathrm{Zn}$ & $\mathrm{Cu}$ & $\mathrm{HV}_{0.1}$ \\
\hline Tool steel A & 0.5 & 0.3 & 0.3 & 4.0 & 18.4 & 0.3 & - & 8.6 & 2.0 & - & - & - & - & $498 \pm 52$ \\
Tool steel V & 1.1 & 0.5 & 0.4 & 4.5 & 3.2 & 8.5 & 3.7 & - & - & 1.8 & - & - & - & $464 \pm 26$ \\
Tool steel O & 0.39 & 1.0 & 0.4 & 5.2 & 1.4 & 0.9 & - & - & - & - & - & - & - & $260 \pm 7$ \\
Al6016 & - & $1.0-1.5$ & $\begin{array}{c}\text { Max } \\
0.2\end{array}$ & Max & - & - & - & - & - & - & $0.25-0.6$ & $\begin{array}{c}\text { Max } \\
\text { Max }\end{array}$ & $\begin{array}{c}\text { Max } \\
73 \pm 3\end{array}$ \\
\hline
\end{tabular}

referred to as polymer.

\subsection{Specimens and topography}

The tool steel specimens were cylindrical pins of $\varnothing 4 \mathrm{~mm}$ with a flat end and the aluminium samples were flat plates with dimensions $20 \mathrm{~mm} \times 20 \mathrm{~mm} \times$ $1 \mathrm{~m}$. The hBN lubricant was applied on the aluminium samples in liquid form, then left to dry in air at room temperature for $10 \mathrm{~min}$. The polymer lubricant was applied on the tool steel pin samples in a similar manner: few drops of the liquid lubricant were deposited on the pin surface and left to dry in air at room temperature for $5 \mathrm{~min}$.

In order to study the influence of tool steel surface roughness on the tribological behaviour, the tool steel pins were used in as-received ground (areal arithmetic average, Sa $0.24 \pm 0.05 \mu \mathrm{m}$ ) and mirrorpolished (Sa $0.03 \pm 0.01 \mu \mathrm{m})$ conditions. These specimens will be referred to as AR for the asreceived and MP for mirror-polished throughout the text.

An example of the as-received surface topographies of tool steel O pins is shown in Figs. 2(a) and 2(b). All of the pins exhibited a radially oriented roughness lay, which enabled to position them in any direction with respect to the sliding direction. A typical mirror-polished tool steel surface topography (tool steel O) is shown in Figs. 2(c) and 2(d). After polishing, a slight directionality of the surface lay, but at a significantly lower scale compared to the as-received topography, was observed.

The as-received surface topography of the aluminium alloy samples is shown in Figs. 2(e) and 2(f). The features seen in these images are those typically obtained from the hot rolling process, showing the presence oxidised shingles, gorges, and rolling grooves [1].
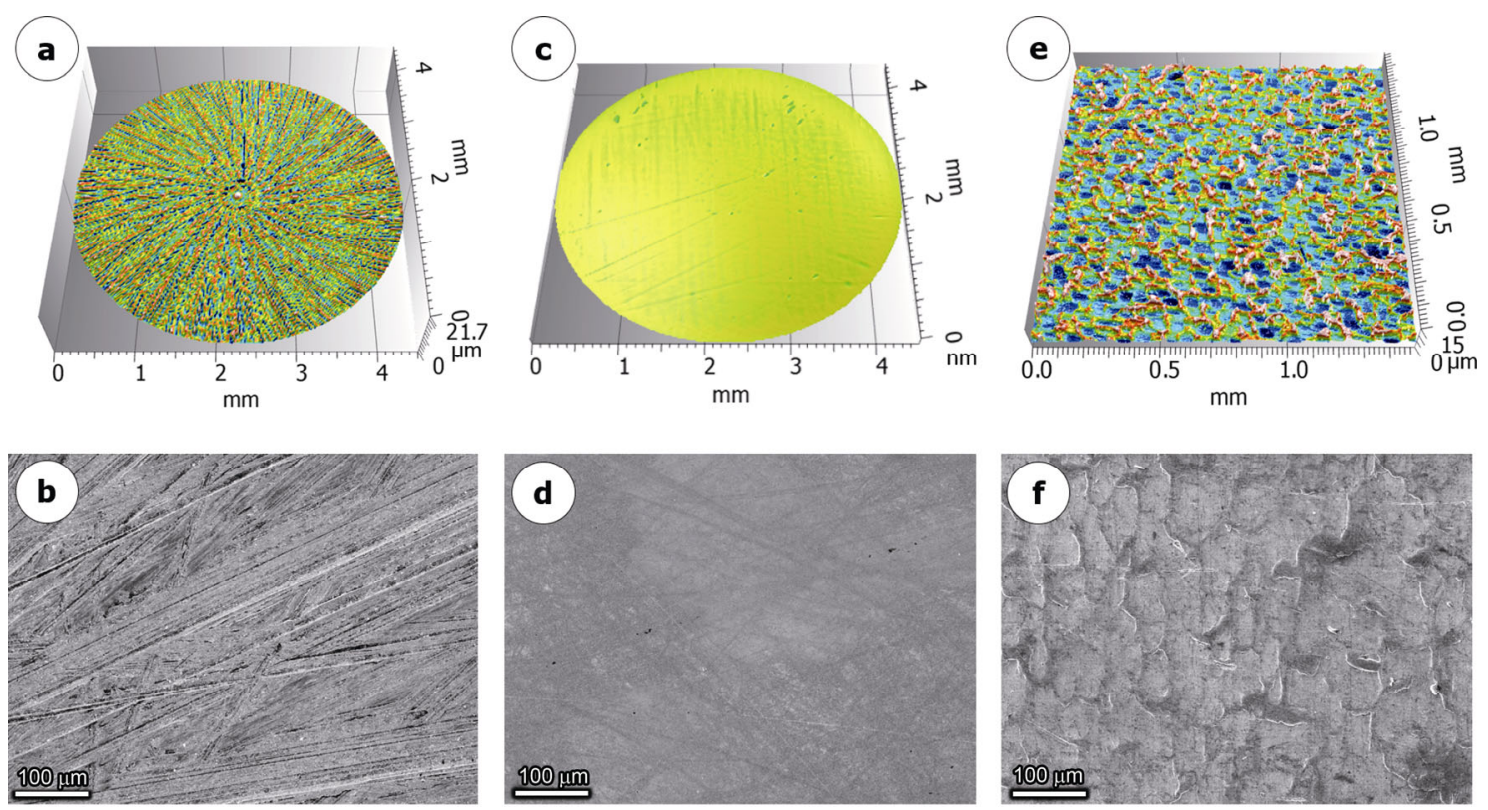

Fig. 2 Surface topographies and SEM micrographs of $(a, b)$ as-received tool steel $\mathrm{O},(\mathrm{c}, \mathrm{d})$ mirror-polished tool steel $\mathrm{O}$, and $(\mathrm{e}$, f) as-received aluminium samples. 
The Sa and reduced peak height (Spk) roughness parameters from three measurements of a $2 \mathrm{~mm} \times 2$ $\mathrm{mm}$ area on the tool steel pins are given in Fig. 3 . It can be noted that the as-received samples for tool steel A exhibited a slightly lower roughness than the other tool steels. The polishing process drastically decreased the Sa and Spk values of all the tool steel samples, as polishing mainly acted on the protruding peaks of the surfaces.

\subsection{Test equipment and procedure}

The tribological tests were carried out using an Optimol SRV ${ }^{\circledR}$ high temperature reciprocating friction and wear tester. This machine utilises an electromagnetic drive to oscillate an upper specimen (pin) against a lower stationary specimen (disc or plate) under a normal load. The load is applied by means of a servo motor and spring deflection mechanism. The lower specimen block incorporates a cartridge heater which enables tests to be performed at temperatures up to $900{ }^{\circ} \mathrm{C}$. A computerised control

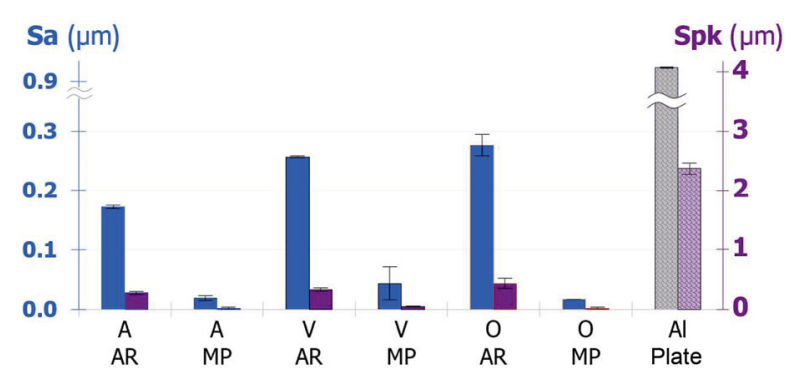

Fig. 3 Average areal roughness parameters of the different samples (ISO $25178, \lambda_{\mathrm{c}}=0.25 \mu \mathrm{m}$ ). system allows data acquisition and control of the applied load, cartridge block temperature, stroke length, and frequency of the oscillatory movement during the tests. The configuration chosen for this study was a flat-on-flat (pin on plate) contact (as exemplified in Fig. 4). The test parameters are given in Table 2. The nominal contact pressure was $1 \mathrm{MPa}$, in accordance to typical contact pressures observed in the hot sheet metal forming processes. A temperature of $300{ }^{\circ} \mathrm{C}$ was chosen, compromising realistic elevated forming temperatures and temperatures that the lubricants could withstand. The stroke was set to $4 \mathrm{~mm}$ in order for the entire surface of the pins to move out of contact with the centre of the wear track on the aluminium surface. The duration of $30 \mathrm{~s}$ was chosen in order to get past the running-in period while avoiding too long contact time $(30 \mathrm{~s}$ corresponds to $3 \mathrm{~m}$ of total sliding distance in these tests), in order to prevent depletion of lubricant and occurrence of severe galling. The short contact time is also representative of hot forming applications where the total forming and quenching operation is typically around $10 \mathrm{~s}$ [27].

The aluminium alloy samples were subjected to an in-situ solubilisation heating cycle (shown in Fig. 4) before the onset of sliding. It involved heating

Table 2 Test parameters used in the tribological tests.

\begin{tabular}{cccccc}
\hline $\begin{array}{c}\text { Load } \\
(\mathrm{N})\end{array}$ & $\begin{array}{c}\text { Contact } \\
\text { pressures } \\
(\mathrm{MPa})\end{array}$ & $\begin{array}{c}\text { Test } \\
\left({ }^{\circ} \mathrm{C}\right)\end{array}$ & $\begin{array}{c}\text { Stroke } \\
(\mathrm{mm})\end{array}$ & $\begin{array}{c}\text { Sliding } \\
\text { frequency } \\
(\mathrm{Hz})\end{array}$ & $\begin{array}{c}\text { Test } \\
\text { duration } \\
(\mathrm{s})\end{array}$ \\
\hline 10 & 0.8 & 300 & 4 & 12.5 & 30 \\
\hline
\end{tabular}
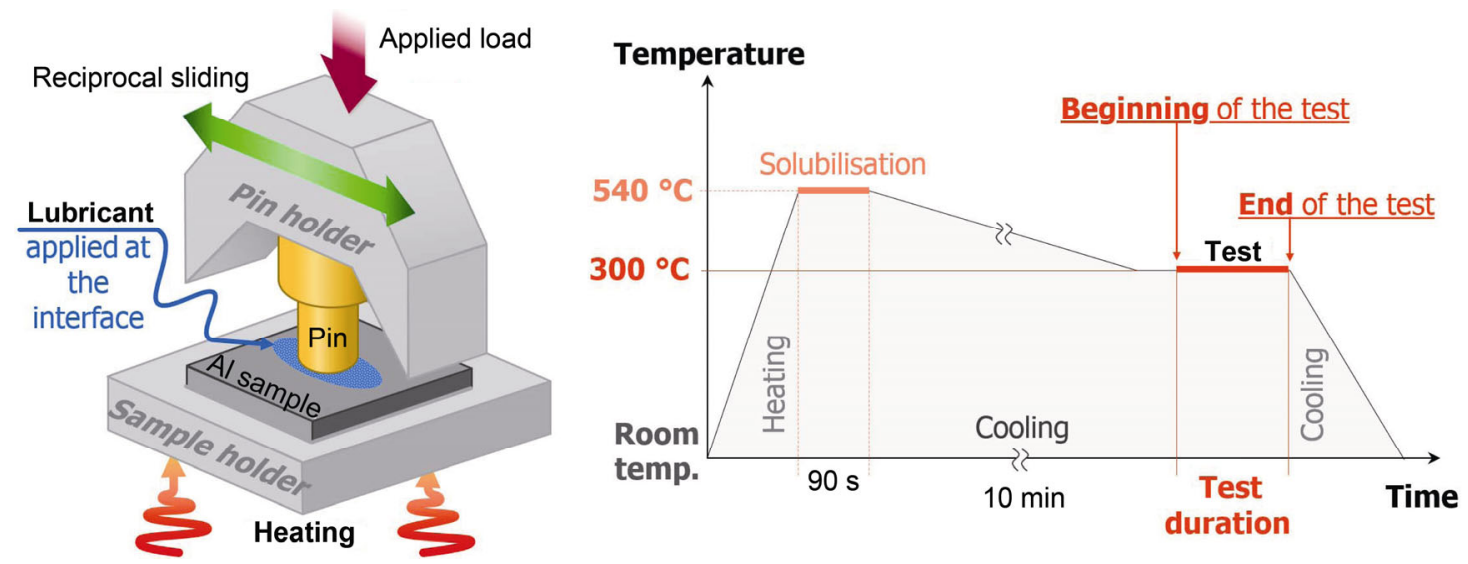

Fig. 4 Sketch of the $\mathrm{SRV}^{\circledR}$ test set-up and the heat cycle (not to scale) applied to the aluminium specimen only. 
up to $540{ }^{\circ} \mathrm{C}$ (dwell time of $90 \mathrm{~s}$ ) followed by cooling down to the test temperature. Since the test equipment does not have an active cooling system, a resting time for cooling and stabilisation of temperature of around $10 \mathrm{~min}$ was used. After the resting time elapsed, the tribotest commenced. The pin specimens were not actively heated prior to or during the tribotest.

The heating cycle is not intended to exactly simulate that of a forming process, but rather to expose the aluminium to a similar thermal history as that during hot forming.

The test procedure involved aligning both samples to ensure good contact and to eliminate edge effects during sliding. The lubricant was then applied (following the procedure stated in Section 2.2) and the heating cycle of the aluminium alloy specimen was started. During this stage, the samples were kept separated from each other. After cooling down to the test temperature, the pin was brought into contact with the aluminium sample, the test load was applied, and the tribotest was initiated.

The surfaces of the specimens were analysed before and after the tribotests. The topography of the samples was measured using a Zygo NewView $730{ }^{\circledR} 3 \mathrm{D}$ optical surface profiler. The friction and wear mechanisms were also analysed by using scanning electron microscopy (SEM) and energy dispersive spectroscopy (EDS).

\section{Results and discussion}

The results obtained from the tribological tests as well as from the post-test analysis are presented and discussed in this section.

\subsection{Dry sliding tests}

The average coefficients of friction (COF) obtained from the dry reference tests are shown in Fig. 5 (darkest bars). The friction level for each tribopair reached the cut-off value of the friction force sensor (2.5). The friction increased to the maximum value directly from the beginning of the test, due to instantaneous severe adhesion. This sharp rise was observed irrespective of the tool steel composition. The influence of tool steel surface topography was not studied under dry conditions, as only negligible improvements have been reported in previous studies $[9,28]$.

The main wear mechanism observed when using the as-received tool steel samples was severe adhesion, as described in Ref. [29], and transfer of the aluminium onto the tool steel surface (see Fig. 6). The transfer mechanism progressed from initiation of aluminium pick-up, due to the ploughing action of the harder tool steel asperities, followed by agglomeration of the wear particles and build-up, finally leading to the development of thick aluminium lumps on the tool steel surface. Lumps were preferentially located at the grooves with perpendicular orientation to the sliding direction, as highlighted in Fig. 6(b). This aluminium transfer process has previously been observed by Heinrichs et al. [28]. In their study,

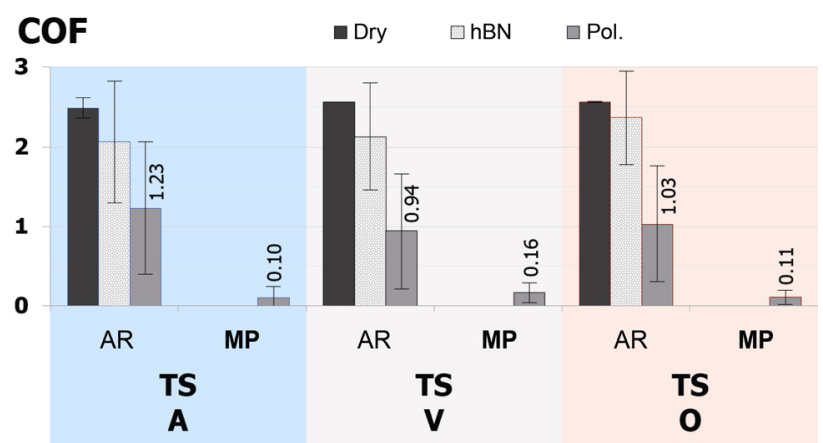

Fig. 5 Average friction levels over the last $25 \mathrm{~s}$ of the tribotests for all the test configurations (load $10 \mathrm{~N}$, stroke length $4 \mathrm{~mm}$, frequency $12.5 \mathrm{~Hz}$, temp. $300^{\circ} \mathrm{C}$ ).
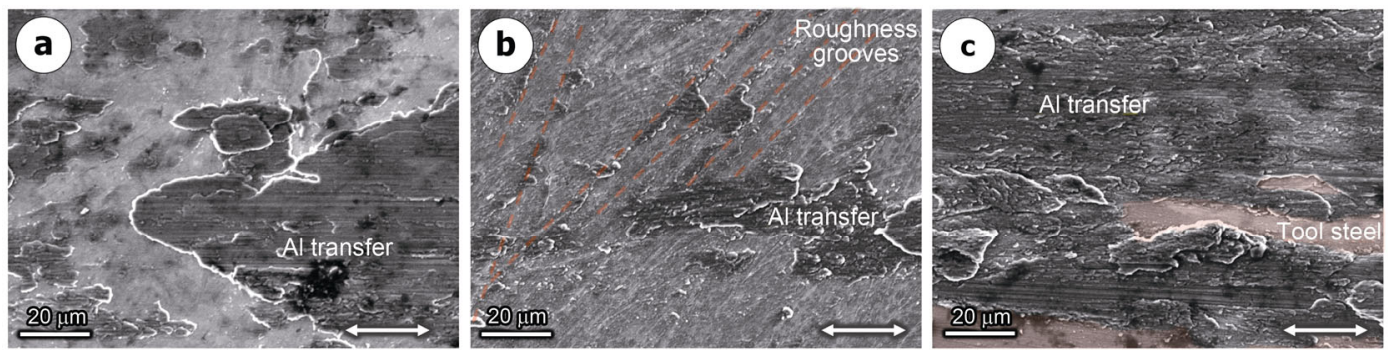

Fig. 6 SEM micrographs of (a) tool steel A, (b) tool steel V, and (c) tool steel O surface obtained from the dry sliding test, showing the heavy aluminium transfer layer ( $\leftrightarrow$ indicates the sliding direction). 
they investigated the transfer initiating from polishing scratches on mirror-polished diamond-like carbon (DLC) coatings. Their suggested mechanism for material transfer (initiation, progressive pick-up, and buildup) correlates well with the observations in the present study. Pujante et al. [9] also concluded that in dry conditions the surface roughness peaks of the tool steel impact material transfer. The topography of their ground samples led to mechanical ploughing, the creation of initiation sites for further transfer, and wear debris entrapment. Their observations of the material transfer features are thus correlating with those obtained in the present research.

\subsection{Lubricated sliding tests}

\subsubsection{Hexagonal boron nitride}

All tribotests performed using the hBN lubricant resulted in early lubricant failure. As shown in Fig. 7 , high and unstable friction was obtained irrespective of the tool steel composition. The friction levels reached the COF cut-off value of the sensor during most of the test duration. Sudden drops in the friction levels for a few seconds were observed during the initial stage but these were followed by a rapid increase to the maximum COF value. The short periods with lower friction coefficients explains the high standard deviation observed in Fig. 5.

The appearance of the transferred material onto the surface of tool steel $\mathrm{O}$, for the dry and hBNlubricated tests, is shown in Fig. 8. Similar mechanisms were also observed on the other tool steels. Sever adhesion was identified again as the main wear mechanism [29]. The transfer layer that was formed in case of tests with the hBN lubricant is a buildup of adhered and smeared aluminium lumps but

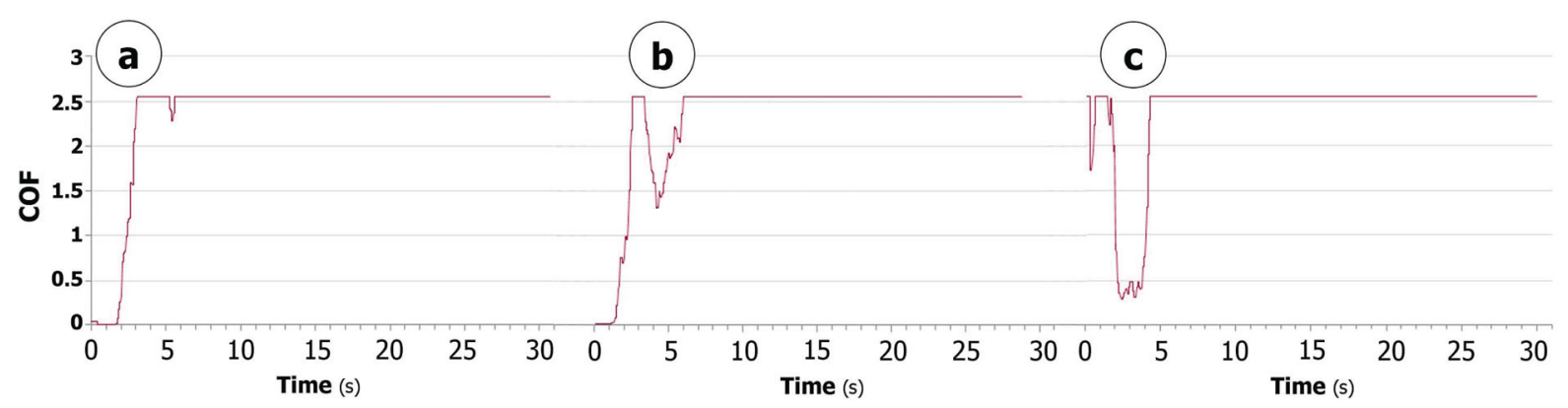

Fig. 7 Evolution of the COF during the hBN lubricated tribotest for the as-received (a) tool steel A, (b) tool steel V, and (c) tool steel $\mathrm{O}$ samples (load $10 \mathrm{~N}$, stroke length $4 \mathrm{~mm}$, frequency $12.5 \mathrm{~Hz}$, temp. $300^{\circ} \mathrm{C}$ ).
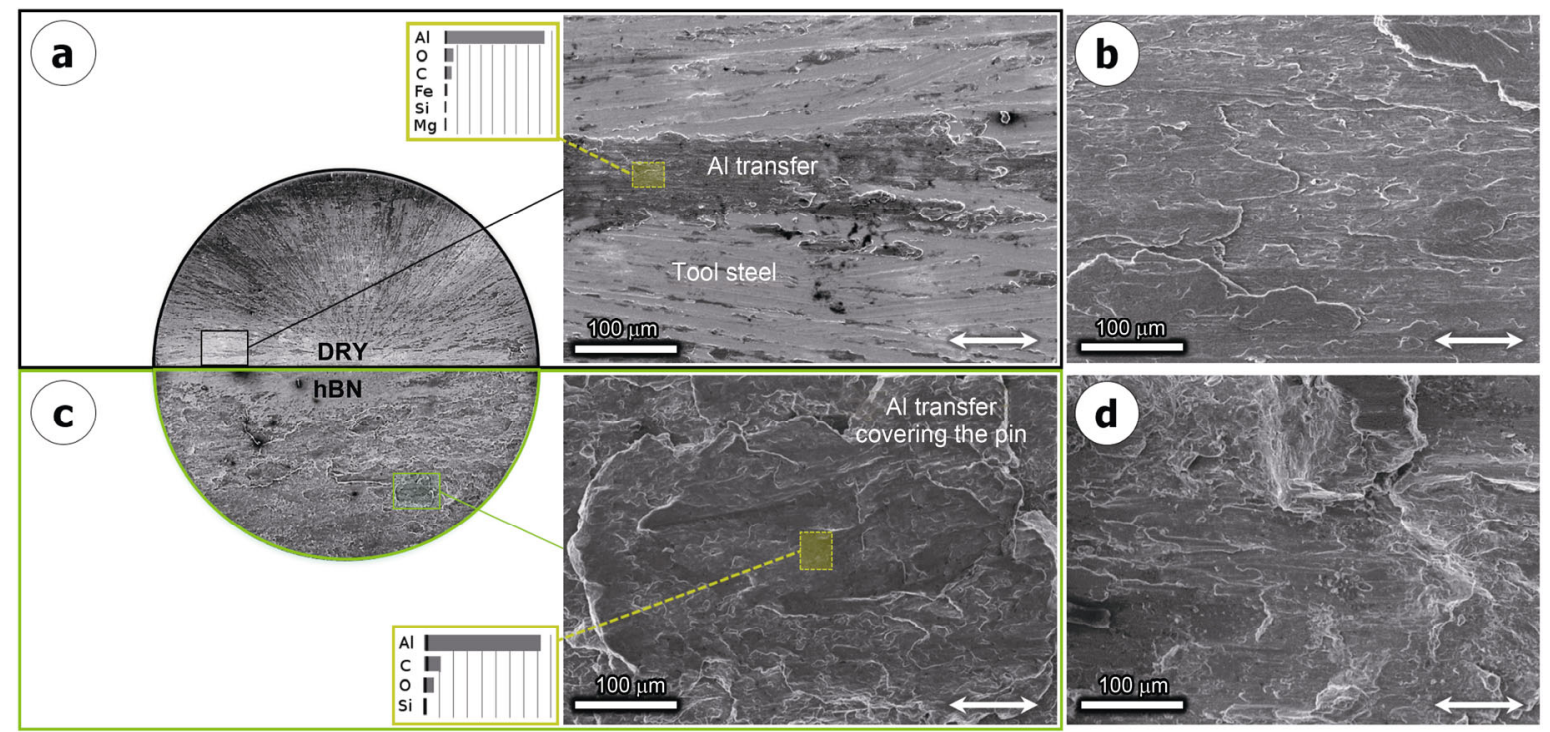

Fig. 8 SEM micrographs of the (a) pin and (b) aluminium surface after a dry sliding test vs. (c) pin and (d) aluminium surface after a hBN lubricated test, both using as-received tool steel $\mathrm{O}$ at $30 \times$ and $200 \times$ magnification ( $\leftrightarrow$ indicates the sliding direction). 
their size is much larger and less uniform than the agglomerated lumps in the dry condition (as observed when comparing Fig. 8(a) and Fig. 8(c)). The transfer observed after the hBN lubricated tests also covered a larger area on the pin samples. The EDS analysis revealed that the transferred material consisted of aluminium, silicon, and traces of the lubricant particles as well as oxygen. The aluminium counter surface also showed more damage compared to that in the dry condition (Figs. 8(b) and 8(d)). Its surface was characterised by deeper and less uniform grooves due to the severe material removal.

The abrupt removal of the lubricant from the contact zone can explain the fact that the tests using this lubricant clearly resulted in a worse tribological behaviour. The poor adhesion of the hBN lubricant to the contacting surfaces led to easy flaking off. The removal was also facilitated due to the hBN particle size, concentration, and the carrier fluid. The lubricant was water-based and with a relatively small particle size $(\sim 5 \mu \mathrm{m})$. During the heating cycle, the water evaporates and leaves the hBN particles free within the contact, thus facilitating their easy removal from the contact, also observed in other studies [19]. However, other carrier fluids, particle size, and concentrations have shown good behaviour of hBN lubricants, when tested at low temperature $[19,30]$.

The hBN lubricant was thus only present in the contact at the very beginning of the sliding and thereafter it was rapidly removed as the test progressed. This sudden removal led to a sharp transition from the initial lubricated contact to a dry aluminiumtool steel contact. Therefore, there was no runningin period, and ploughing of the aluminium occurred immediately after lubricant failure resulting in more severe contact conditions.

\subsubsection{Polymer lubricant}

\subsubsection{As-received tool steels}

The friction results from tests with the as-received tool steels samples and polymer lubricant showed some tribological improvement compared to those in the dry and hBN lubricated tests. The polymerlubricated tests showed a reduction in the average friction level by half (as seen in Fig. 5). As shown in Fig. 9, an initial increase in friction is followed by a decrease and a short steady period with relatively low friction (COF around 0.3 for approximately $5 \mathrm{~s})$. Towards the end of the test, friction becomes unstable and increases. The friction behaviour is similar for all tool steel compositions as well as to that in dry and hBN lubricated conditions.

The post-test analysis of the worn surfaces revealed the formation of a tribolayer on the pin surface, as seen in Fig. 10. This is exemplified with tool steel O but similar tribolayers were also observed for the other tool steels. Chemical analysis revealed that the tribolayer contains a high concentration of carbon originating from the polymer lubricant. This layer was load bearing and prevented direct aluminiumtool steel contact. However, Fig. 10(a) shows that the tribolayer fractured, which led to the formation of large debris, variation in thickness, and partial removal of the tribolayer. The areas where the tribolayer was removed were found to be the preferential sites for aluminium transfer to take place.

On one hand, the transfer of aluminium at these sites can be attributed to the tool steel topography, which would act as ploughing asperities, scraping

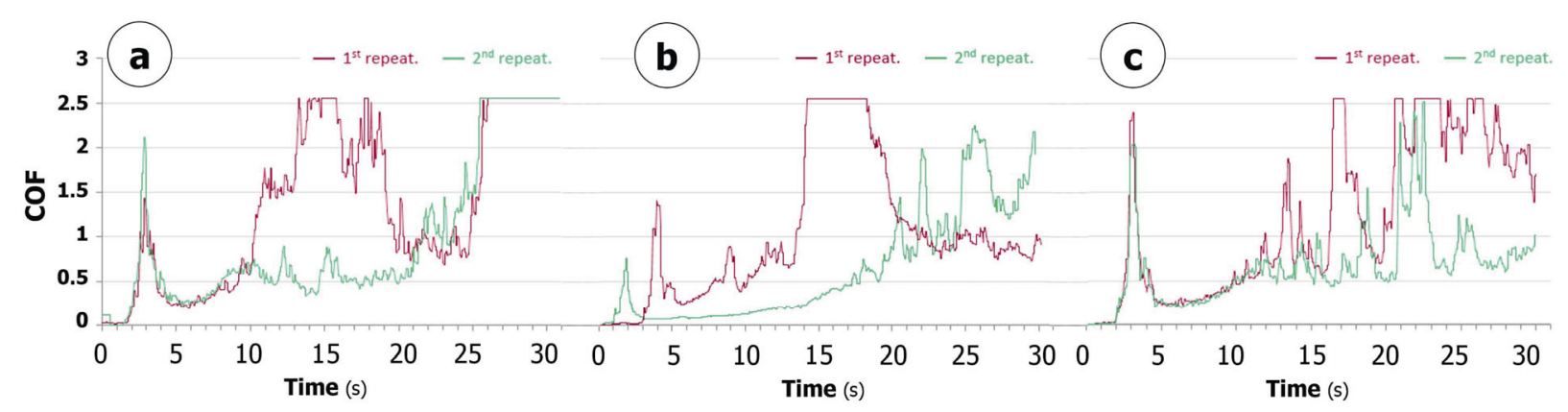

Fig. 9 Evolution of the COF during the polymer lubricated tribotests for the as-received (a) tool steel A, (b) tool steel V, and (c) tool steel $\mathrm{O}$ (load $10 \mathrm{~N}$, stroke length $4 \mathrm{~mm}$, frequency $12.5 \mathrm{~Hz}$, temp. $\left.300{ }^{\circ} \mathrm{C}\right)$. 

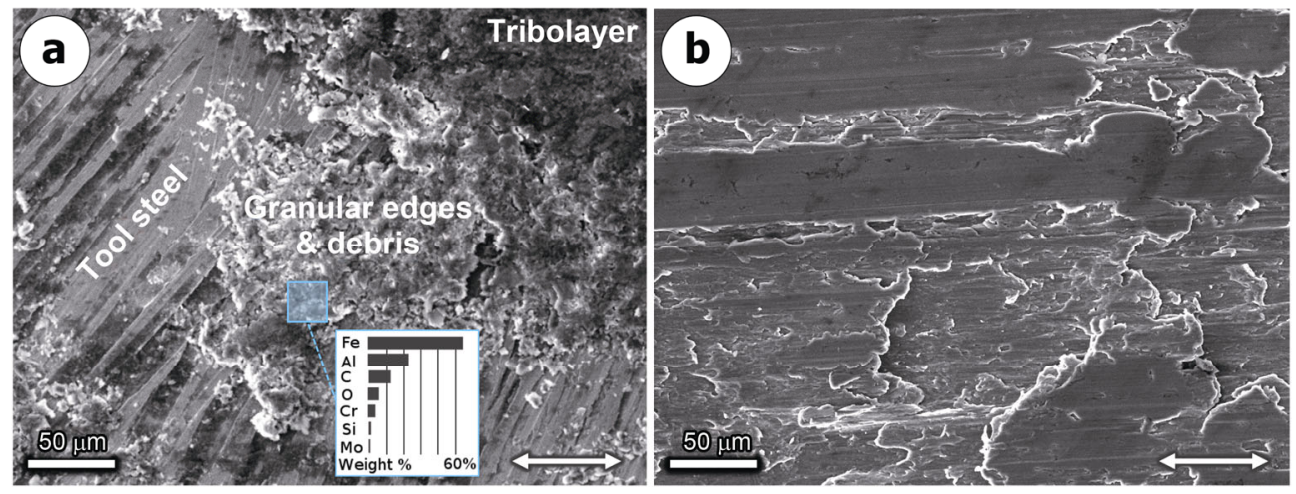

Fig. 10 SEM micrographs of the surface of the (a) as-received tool steel $O$ and (b) aluminium sample surface obtained from the polymer lubricated test at $200 \times$ magnification, showing the tribolayer developed on the pin and the wear of the aluminium ( $\leftrightarrow$ indicates the sliding direction).

off the lubricant then abrading the soft aluminium. The tendency of aluminium transfer to increase after primary transfer takes place has been studied by Heinrichs et al. [31]. They observed that once it is initiated, the high chemical affinity of aluminium towards itself and coarsening of the surface features rapidly led to increased material transfer during the successive cycles. In the present research, a parallel can be drawn: the tribolayer failure leads to the primary material transfer and then further transfer rapidly grows. The aluminium counter surface showed less severe damage but similar mechanism as in dry sliding conditions (as seen Fig. 10(b)), supporting the idea of rapidly increasing material transfer. Nevertheless, the transfer is significantly less in the polymer lubricated tests compared to that in the dry and hBN lubricated ones, as the tribolayer reduces the occurrence of primary transfer. On the other hand, Wan et al. [20] reported that inorganic polymer additives react to create stable lubricating and anti-wear layers in extreme contact conditions (e.g. high temperatures or pressures) against metals. Those additives could also lead to lower friction and wear by preventing overheating. Both of those observations could explain the beneficial effect of the lubricant used in the present study, although its composition is different.

The observed wear mechanisms correlate well with the friction behaviour. The increase in friction in the beginning of the test occurs before the tribolayer has formed a stable layer. Once the tribolayer is established, the tribological behaviour improves. As the tribolayer breaks down, the friction increases and becomes unstable as severe adhesion takes place.

\subsubsection{Mirror-polished tool steels}

As can be seen in Fig. 5, mirror-polished tool steel samples led to a reduction of friction by 10 times compared to the as-received tool steel pin specimens. Furthermore, a much more pronounced improvement in terms of frictional stability was also observed as the standard deviation is 6 times lower compared to the as-received specimens. Figure 11 shows the evolution of the coefficient of friction with time during the tests with mirror-polished specimens. The friction levels remained below 0.3 during almost

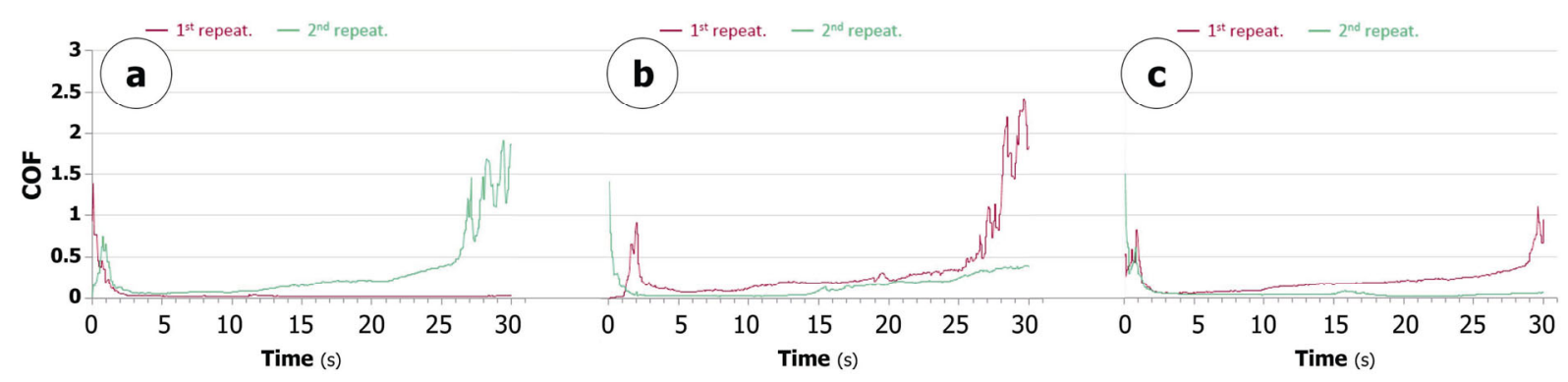

Fig. 11 Evolution of the COF during the polymer lubricated tribotests for the mirror-polished (a) tool steel A, (b) tool steel V, and (c) tool steel $\mathrm{O}$ pin samples (load $10 \mathrm{~N}$, stroke length $4 \mathrm{~mm}$, frequency $12.5 \mathrm{~Hz}$, temp. $300{ }^{\circ} \mathrm{C}$ ). 
the entire test duration, and in some cases it was down to 0.1. An increase in the friction coefficient was only observed towards the end of the tests, whereas for the as-received specimens, frictional instabilities occurred throughout the entire test (Fig. 9). As has been previously observed, the behaviour for the three different tool steels was similar. It is clear that the tool steel surface roughness plays a critical role in the stability of friction under high-temperature lubricated conditions.

As shown in Fig. 5, the mirror polished sample with the highest roughness value was tool steel V, followed by tool steel A and tool steel O. This can be attributed to the size and height of the protruding carbides after the polishing process (shown in Fig. 12). The surface coverage and size of the protruding carbides are given in Fig. 13. The protruding carbides act as asperities and result in a reduced real area of contact (compared to a nominally flat surface) which promote failure of the protective tribolayer in the contact during sliding. A direct correlation between the surface topography of the tool steels and the friction stability has been observed; the friction behaviour using tool steel $\mathrm{V}$ is the least stable (Fig. 11(b)), followed by tool steel A, which has the intermediate surface roughness (Fig. 11(a)). The most stable friction was obtained with tool steel $\mathrm{O}$ (Fig. 11(c)), which had the smoothest surface topography and the smallest carbides (shown in Figs. 12(c) and 13). Interestingly, even though tool steel A had bigger carbides, they covered a larger area on the contact surface, and were found to be protruding less than those in tool steel V. This suggests that the main factor triggering the failure of the lubricant is their height as well as the area coverage.
When examining the worn surfaces after the tribotests, the compact and smooth tribolayers covering most of the tool steel pin surfaces were observed (Fig. 14), similar type of tribolayers was observed for all three tool steels. The tribolayers were composed of elements from the lubricant, i.e., carbon, oxygen, and silicon. At the locations where tribolayer failure had initiated, traces of aluminium transfer were detected. These observations explain the unstable COF observed at the end of the tests (Fig. 11). Furthermore, in the cases showing the lowest and most stable friction behaviour (for instance the $1^{\text {st }}$ repetition in Fig. 11(a) and the $2^{\text {nd }}$ repetition in Fig. 11(c)), no material transfer was detected on the tool steel surfaces. This suggests that the tribolayers in those cases did not fail and thus prevented direct aluminium-tool steel contact for the entire test duration.

Considering the areas where adhesion took place (e.g. tribolayer failure areas), the protruding carbides were found to act as initiation sites for the aluminium transfer (Fig. 15). Tool steel V (Fig. 15(b)) shows the initiation and development of transferred aluminium lumps from the carbide edges, while the surrounding matrix clearly shows less material transfer. Pujante et al. [9] also observed minor amounts of material transfer onto mirrorpolished tool steel samples, as thin layers, growing into small patches, similar to those observed in Fig. 15. They concluded that nucleation points on the polished tool steel were responsible for the material transfer, although in their case, those initiation sites were created from abrasion of the tool steel by the aluminium oxides. The specific preferential initiation of aluminium transfer at protruding sites has also been reported in extensive works from
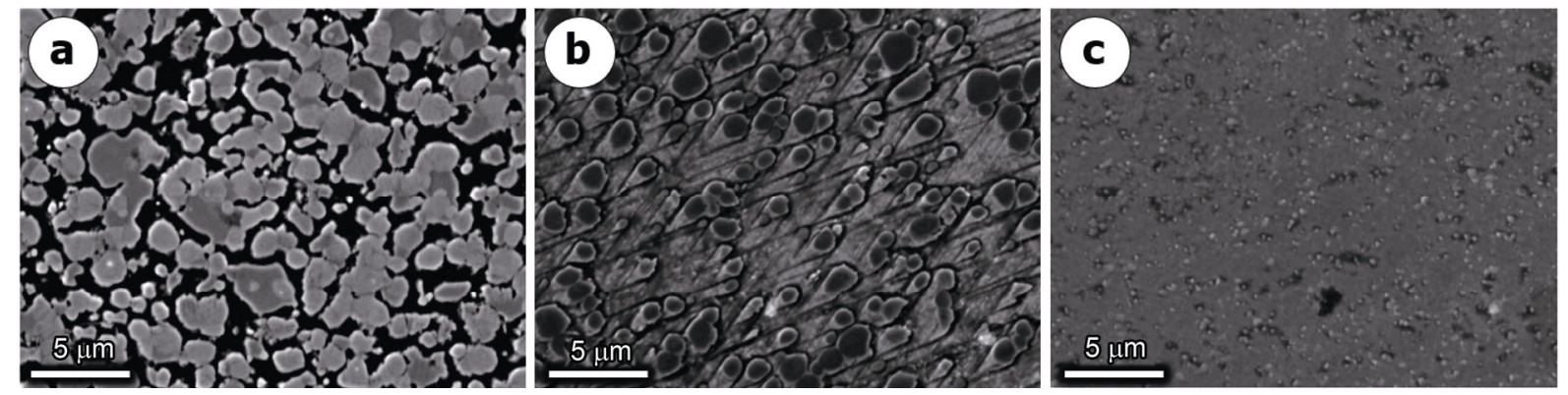

Fig. 12 SEM micrographs of the unworn mirror-polished (a) tool steel A, (b) tool steel V, and (c) tool steel O pin samples at $5,000 \times$ magnification, showing the different carbides revealed after the polishing process. 
Heinrichs et al. [28, 31]. Their studies involved mirror-polished DLC coating with protruding carbides, which, similar to the present study, acted as initiation sites for aluminium transfer.

Considering the aluminium counter surface, some interesting features have been observed after sliding against mirror polished tool steel (shown in Fig. 14(b)). The initial rough surface is still visible beneath a plastically deformed layer (highlighted in Fig. 14(b)). This smooth flat topography forms through flattening of the protruding shingles (covering the as-received aluminium surface, as shown in Figs. 2(e) and 2(f)) during interaction with the polished tool steel counter surface (shown in Figs. 2(c) and 2(d)). The deformation of the aluminium is facilitated by the hardness difference between the specimens in contact, which is even more pronounced at $300{ }^{\circ} \mathrm{C}$. Compared to the as-received tool steel specimens, the real area of contact with mirror polished surfaces increases and is further increased with the flattening of the aluminium surface. This larger contact area contributes to reduced local contact stresses and the formation of the tribolayer over a larger surface area, than in the as-received cases, where roughness grooves act as stress concentration points and lubricant scraping features. This effectively prevents direct metal-to-metal contact and maintains a low and stable friction level.

\section{Conclusions}

In this study, the high temperature tribological

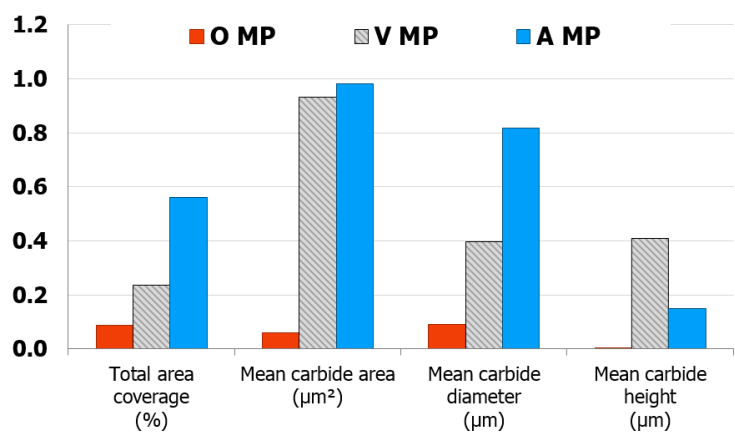

Fig. 13 Surface coverage and size of the protruding carbides on the mirror-polished surfaces (total measured area $55 \mu \mathrm{m}^{2}$, ISO $\left.25178, \lambda_{\mathrm{c}} 2.5 \mu \mathrm{m}\right)$.
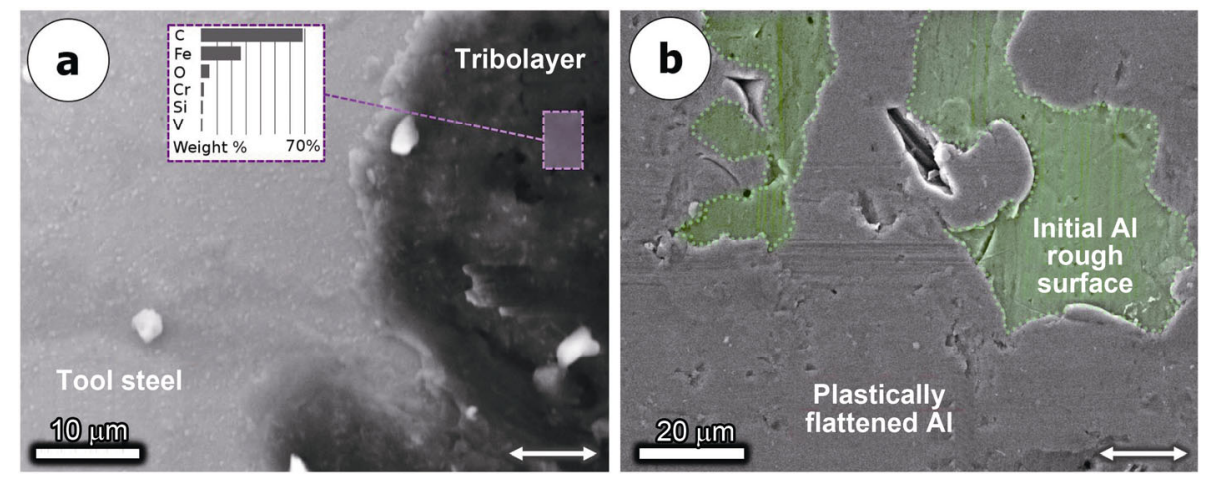

Fig. 14 SEM micrographs of the surface of the (a) mirror-polished tool steel $O$ and (b) flattened aluminium topography obtained from the polymer lubricated test ( $\leftrightarrow$ indicates the sliding direction).
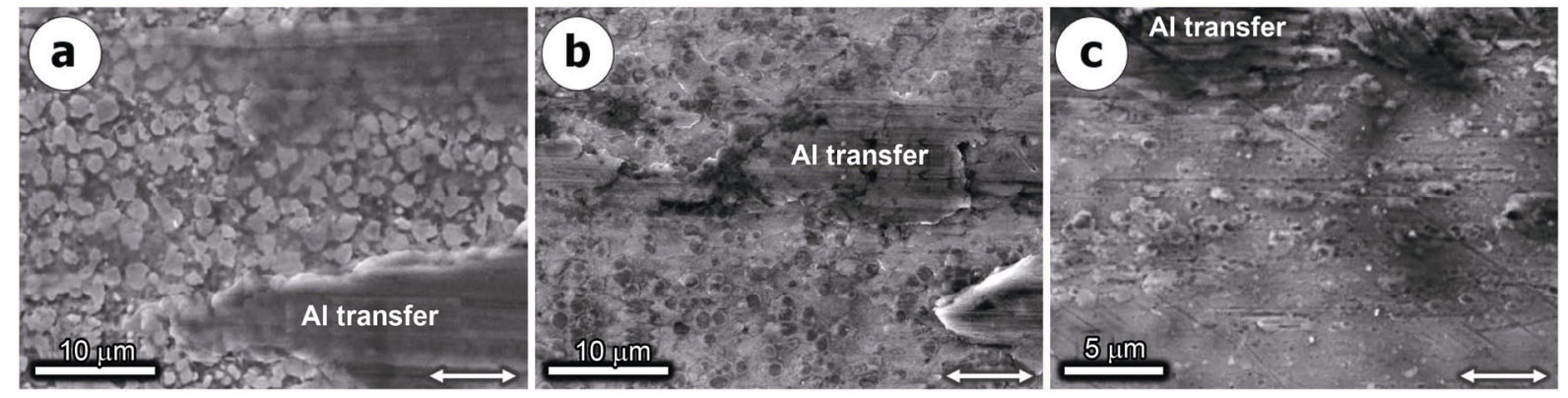

Fig. 15 SEM micrographs of the worn mirror-polished (a) tool steel A (using $15 \mathrm{kV}$ ), (b) tool steel V (15 kV), and (c) tool steel $\mathrm{O}(10 \mathrm{kV})$ pin samples at 5,000× magnification, showing the initiation of aluminium transfer from the protruding carbides ( $\leftrightarrow$ indicates the sliding direction). 
behaviour of three different tool steels with different surface topographies has been investigated during sliding against aluminium under dry and lubricated conditions. The salient conclusions from this work are as follows:

1) Dry sliding at high temperature results in instantaneous adhesion and consequently high friction.

2) The hBN lubricant selected for this study was found ineffective as a result of poor adhesion to the interacting surfaces and easy removal from the sliding interface.

3) The use of a polymer-silicon based lubricant leads to reduced friction and material transfer as a result of formation of a carbon-rich tribolayer on the tool steel surface.

4) The tool steel chemical composition does not significantly affect the tribological response under the studied test conditions.

5) The tool steel surface roughness has a significant impact on the frictional behaviour and the severity of material transfer. Even protruding carbides on a mirror polished tool steel surface can act as initiation sites for aluminium transfer.

6) The combination of reduced tool steel roughness and polymer-silicon lubrication results in the best improvements in terms of frictional stability and material transfer.

\section{Acknowledgements}

The authors would like to acknowledge Swerea IVF for the financial and material support as well as their inputs for the realisation of this study.

Open Access: This article is licensed under a Creative Commons Attribution 4.0 International License, which permits use, sharing, adaptation, distribution and reproduction in any medium or format, as long as you give appropriate credit to the original author(s) and the source, provide a link to the Creative Commons licence, and indicate if changes were made.

The images or other third party material in this article are included in the article's Creative Commons licence, unless indicated otherwise in a credit line to the material. If material is not included in the article's Creative Commons licence and your intended use is not permitted by statutory regulation or exceeds the permitted use, you will need to obtain permission directly from the copyright holder.

To view a copy of this licence, visit http://creativecommons.org/licenses/by/4.0/.

\section{References}

[1] Gali O A. Micro-mechanisms of surface defects induced on aluminum alloys during plastic deformation at elevated temperatures. Ph.D Thesis. Windsor (UK): University of Windsor, 2017.

[2] Fan X B, He Z B, Yuan S J, Zheng K L. Experimental investigation on hot forming-quenching integrated process of 6A02 aluminum alloy sheet. Mater Sci Eng A 573: 154-160 (2013)

[3] Mendiguren J, de Argandona E S, Galdos L. Hot stamping of AA7075 aluminum sheets. IOP Conf Ser Mater Sci Eng 159(1): 012026 (2016)

[4] Dong Y C, Zheng K L, Fernandez J, Li X Y, Dong H S, Lin J G. Experimental investigations on hot forming of AA6082 using advanced plasma nitrocarburised and CAPVD WC: C coated tools. J Mate Process Technol 240: 190-199 (2017)

[5] Zheng K L, Lee J, Xiao W C, Wang B Y, Lin J G. Experimental investigations of the in-die quenching efficiency and die surface temperature of hot stamping aluminium alloys. Metals 8(4): 231 (2018)

[6] Dwivedi D K. Sliding temperature and wear behaviour of cast Al-Si-Mg alloys. Mater Sci Eng A 382(1-2): 328-334 (2004)

[7] Pujante J, Pelcastre L, Vilaseca M, Casellas D, Prakash B. Investigations into wear and galling mechanism of aluminium alloy-tool steel tribopair at different temperatures. Wear 308(1-2): 193-198 (2013)

[8] Beynon J H. Tribology of hot metal forming. Tribol Int 31(1-3): 73-77 (1998)

[9] Pujante J, Vilaseca M, Casellas D, Riera M D. The role of adhesive forces and mechanical interaction on material transfer in hot forming of aluminium. Tribol Lett 59(1): $10(2015)$

[10] Hosford W F, Caddell R M. Metal Forming: Mechanics and Metallurgy. 4th ed. Cambridge (UK): Cambridge University Press, 2011.

[11] Das S, Morales A T, Riahi A R, Meng-Burany X, Alpas A T. Role of plastic deformation on elevated temperature tribological behavior of an Al-Mg alloy (AA5083): A friction mapping approach. Metall Mater Trans A 42(8): 2384-2401 (2011)

[12] Das S, Biswas S K. Boundary lubricated tribology of an 
aluminium-silicon alloy sliding against steel. Tribol Lett 17(3): 623-628 (2004)

[13] Archard J F, Hirst W. The wear of metals under unlubricated conditions. Proc Roy Soc A Math Phys Sci 236(1206): 397-410 (1956)

[14] Elmadagli M, Alpas A T. Progression of wear in the mild wear regime of an A1-18.5\% Si (A390) alloy. Wear 261(3-4): 367-381 (2006)

[15] Zhang J, Alpas A T. Transition between mild and severe wear in aluminium alloys. Acta Mater 45(2): 513-528 (1997)

[16] Subramanian C. Wear properties of aluminium-based alloys. In Surface Engineering of Light Alloys: Aluminium, Magnesium and Titanium Alloys. Dong H S, Ed. Cambridge, Elsevier, 2010: 40-57.

[17] Krajewski P E, Morales A T. Tribological issues during quick plastic forming. J Mater Eng Perform 13(6): 70009 (2004)

[18] Pelcastre L, Hardell J, Courbon C, Prakash B. Tribological behaviour of Al-Si-coated ultra-high-strength steel during interaction with tool steel at elevated temperatures: Influence of tool steel surface topography parameters on galling. Proc Inst Mech Eng B Eng Manuf 229(8): 1373-1384 (2015)

[19] Rao K P, Wei J J. Performance of a new dry lubricant in the forming of aluminum alloy sheets. Wear 249(1-2): 85-92 (2001)

[20] Wan S H, Tieu A K, Xia Y N, Zhu H T, Tran B H, Cui S G. An overview of inorganic polymer as potential lubricant additive for high temperature tribology. Tribol Int 102: 620-635 (2016)

[21] Chinãs-Castillo F, SPIKES H A. Mechanism of action of colloidal solid dispersions. J Tribol 125(3): 552-557

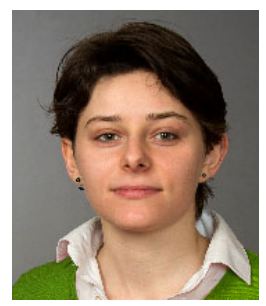

Justine DECROZANT-TRIQUENAUX. She received her M.S. degree in mechanical engineering in 2016 from Ecole Nationale d'Ingénieurs de Saint Etienne (ENISE), France. Then, she was a Ph.D. student at

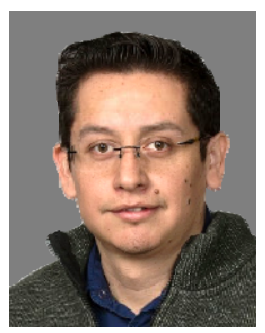

Leonardo PELCASTRE. He received his M.S. degree in the advanced materials science and engineering masters programme in 2008 at Luleå University of Technology, and his Ph.D. degree in machine
(2003)

[22] Erdemir A. Boron-based solid nanolubricants and lubrication additives. In Nanolubricants. Martin J M, Ohmae N, Eds. Chichester: Wiley \& Sons, Ltd, 2008: 203-223.

[23] Sliney H E. Solid lubricant materials for High temperatures-a review. Tribol Int 15(5): 303-315 (1982)

[24] Jiménez A E, Bermúdez M D. Ionic liquids as lubricants for steel-aluminum contacts at low and elevated temperatures. Tribol Lett 26(1): 53-60 (2007)

[25] Heinrichs J. On transfer of work material to tools. Ph.D Thesis. Uppsala(Sweden): Uppsala University, 2012.

[26] Tarasov S Y, Filippov A V, Kolubaev E A, Kalashnikova $\mathrm{T}$ A. Adhesion transfer in sliding a steel ball against an aluminum alloy. Tribol Int 115: 191-198 (2017)

[27] Karbasian H, Tekkaya A E. A review on hot stamping. $J$ Mater Process Technol 210(5): 2103-2118 (2010)

[28] Heinrichs J, Olsson M, Jacobson S. New understanding of the initiation of material transfer and transfer layer build-up in metal forming - In situ studies in the SEM. Wear 292-293: 61-73 (2012)

[29] Reddy A S, Bai B N P, Murthy K S S, Biswas S K. Mechanism of seizure of aluminium-silicon alloys dry sliding against steel. Wear 181-183: 658-667 (1995)

[30] Podgornik B, Kafexhiu F, Kosec T, Jerina J, Kalin M. Friction and anti-galling properties of hexagonal boron nitride (h-BN) in aluminium forming. Wear 388-389: 2-8 (2017)

[31] Heinrichs J, Olsson M, Jacobson S. Mechanisms of material transfer studied in situ in the SEM: Explanations to the success of DLC coated tools in aluminium forming. Wear 292-293: 49-60 (2012)

the Luleå University of Technology, Sweden. Her Ph.D. degree will be defended in mechanical engineering. Her research areas include high temperature tribology with a focus on sheet metal forming of aluminium.

elements in 2013 at the same university. His current position is a university lecturer at Luleå university of technology and his research focuses on high temperature tribology, wear of materials, surface engineering, and tribomaterials for tribological applications. 


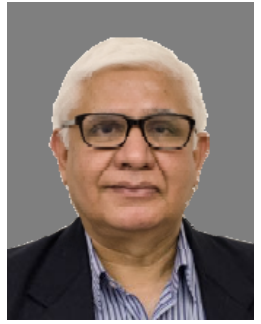

Braham PRAKASH. He is presently distinguished visiting professor at Tsinghua University (China) and professor emeritus at Luleå University of Technology (Sweden). He obtained Ph.D. (tribology) degrees (1993) from Indian Institute of Technology Delhi (India). He was a professor

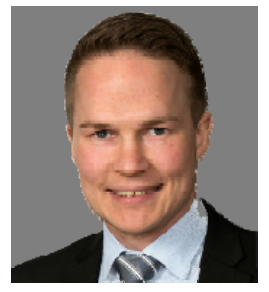

Jens HARDELL. He received his M.S. degree in mechanical engineering in 2005 and Ph.D. degree in machine elements in 2009 from Luleå University of Technology, Sweden. His current and head of Tribolab at the Division of Machine Elements of Luleå University of Technology during 2002-2019. His research \& teaching activities pertain to high temperature tribology; tribology of materials \& lubricants; solid lubricants/self-lubricating coatings; boundary lubrication; tribology of machine components (bearings, gears and seals); analysis of wear problems; and tribotesting.

position is an associate professor at Luleå University of Technology. His main research interests include high temperature tribology, friction and wear in dry contacts, tribomaterials as well as surface engineering for friction and wear control. 